\title{
Can the Fed Predict the State of the Economy? ${ }^{1}$
}

\author{
Tara M. Sinclair \\ Department of Economics \\ George Washington University \\ Washington DC 20052 \\ tsinc@gwu.edu \\ Fred Joutz \\ Department of Economics \\ George Washington University \\ Washington DC 20052 \\ bmark@gwu.edu \\ H. O. Stekler \\ Department of Economics \\ George Washington University \\ Washington DC 20052 \\ hstekler@gwu.edu
}

March 2, 2010

JEL Codes: C53, E37, E52, E58

Keywords: Forecast Evaluation; Federal Reserve; Systematic Errors; Recessions

\begin{abstract}
Recent research has documented that the Federal Reserve produces systematic errors in forecasting inflation, real GDP growth, and the unemployment rate, even though these forecasts are unbiased. We show that these systematic errors reveal that the Fed is "surprised" by real and inflationary cycles. Using a modified Mincer-Zarnowitz regression, we show that the Fed knows the state of the economy for the current quarter, but cannot predict it one quarter ahead. We further show that even allowing for an asymmetric loss function the Fed does not appear to know the state of the economy one quarter ahead.
\end{abstract}

\footnotetext{
${ }^{1}$ We thank Peter Tinsley and Chao Wei for helpful comments, Lauren Taylor, Warren Carnow, and Kavita Patel for excellent research assistance, the Institute for International Economic Policy for financial support, and participants at the 17th Federal Forecasters Conference for feedback. We also thank an anonymous referee for comments that significantly improved this article. M. Al Sadek's undergraduate thesis provided the stimulus for this paper.
} 


\section{Can the Fed Predict the State of the Economy?}

Monetary policy decisions are based on forecasts of future economic activity. Consequently, the Greenbook forecasts made by the Federal Reserve (Fed) staff have been extensively evaluated. The forecasts are quarterly predictions made several times each quarter with horizons of zero to eight quarters. The staff predicts GDP, its components, various price indices, unemployment, etc. These forecasts should reveal what the Fed knows about the current and future states of the economy.

Recent research has shown that the Fed forecasts contain systematic errors (Joutz and Stekler, 2000). Forecasters overestimated the rate of growth during slowdowns and recessions and underestimated it during recoveries and booms. Similarly, inflation was under-predicted when it was rising and over-predicted when it was declining. Particularly large errors occurred during the 1970s and early 1980s when prices were rising rapidly. ${ }^{1}$

This paper explores the systematic errors in the Greenbook forecasts of real output growth, inflation, and the unemployment rate to determine if these errors reveal what the Fed knows about the state of the US economy. If the staff has information on real and inflationary cycles, it should be incorporated into the forecasts. In this analysis, we modify the MincerZarnowitz (1969) regression to include dummy variables for the NBER-dated recessions and ECRI-dated inflationary cycles. ${ }^{2}$

We first present the data and the modified Mincer-Zarnowitz regressions. Our results

\footnotetext{
${ }^{1}$ Hanson and Whitehorn (2006) also observed these systematic errors but associated them with particular time periods rather than with stages of the business cycle.

${ }^{2}$ Swanson and van Dijk (2006) used a similar technique to explore the role of business cycle asymmetry for the rationality of early data releases. Dynan and Elmendorf (2001) also look at early data releases focusing on real GNP/GDP and find that provisional estimates do not fully capture turning points.
} 
show that the Fed forecasts do not incorporate information on recessions or inflationary cycles into the one-quarter-ahead forecasts. This information is contained in the current quarter forecasts, indicating that the Fed knows the state of the economy for the current quarter, but cannot predict it one quarter ahead. This result is robust even allowing for an asymmetric loss function.

\section{Data}

We examine the Fed's Greenbook current quarter and one quarter-ahead forecasts for the period 1965IV-2003IV³ for three variables: the real output growth rate (GNP until 1991III and GDP from 1991IV on), the GNP/GDP deflator inflation rate, and the unemployment rate. Whenever there are multiple forecasts in each quarter, we use the last one. ${ }^{4}$ The actual data are the NIPA estimates that are released approximately 45 days after the quarter to which they refer. ${ }^{5}$ All data, with the exception of the unemployment rate, are converted into annualized growth rates.

Figures (1a-1d,.., 3a-3d) present data for each variable: the annualized growth rate of real GNP/GDP, the annualized inflation rate as measured by the GNP/GDP deflator, and the unemployment rate. The upper left hand graphs display the historical data used in the analysis. The other quadrants of these figures display, for each series: the current quarter and one quarterahead forecast errors and the forecast revisions between the current quarter and one-quarter-

\footnotetext{
${ }^{3}$ The Greenbook data are only available with a 5-year lag. We obtained our dataset from the PDF files on the Federal Reserve Bank of Philadelphia website.

${ }^{4}$ We use the last forecasts for each quarter because those contain the maximum amount of information on which to base current and next quarter forecasts. Forecasts made within the first 10 days of the next quarter are considered made in the previous quarter because there would be no new information for the subsequent quarter. We also analyzed forecasts made in the middle of the quarter. The results were similar.

${ }^{5}$ Use of the real time data avoids definitional and classification changes and is the most consistently available data set for our sample. The terminology for these data releases has varied over the sample. We obtained similar results using the 90 day releases.
} 
ahead forecasts.

The shaded areas of Figures 1 and 3 represent the dates of these recessions, as defined by the NBER. In Figure 2 the shaded areas represent periods when the inflation rate was increasing (moving from trough to peak). The dates for the periods of the inflation cycle were obtained from Dr. Anirvan Banerji of the Economic Cycle Research Institute (ECRI).

\section{The Modified Mincer-Zarnowitz Regression and Results}

The basic Mincer-Zarnowitz regression is: ${ }^{6}$

$$
A_{t}=\beta_{0}+\beta_{1} F_{t, t-i}+e_{t, t-i} ; \quad i=0,1
$$

where $A_{t}$ and $F_{t, t-i}$ are the actual and predicted values for time $t$. The forecast is conditional on the information available at time $t-i$. When $i=0$, it refers to a current quarter forecast. For a test of informational efficiency, the null hypothesis is: $\beta_{0}=0$ and $\beta_{1}=1$. A rejection of this hypothesis indicates that the forecasts are biased and/or inefficient. The Wald test and the F distribution are used to test this null.

In order to determine whether the forecasts incorporated information about the state of the economy, we modified the Mincer-Zarnowitz regression:

$$
A_{t}=\beta_{0}+\beta_{1} F_{t, t-i}+\beta_{2} D_{t}+e_{t, t-i} ; \quad i=0,1
$$

where $D_{t}$ is a dummy that reflects the state of the economy. In the growth and unemployment equations, it has the value 1 if the economy was in a NBER-dated recession and is zero otherwise. In the inflation equation, the dummy takes on the value 1 from the trough to the peak of the inflation cycle as dated by ECRI, zero otherwise. The joint null hypothesis is:

\footnotetext{
${ }^{6}$ Similar results with respect to the role of the state of the economy can be obtained using the Holden and Peel (1990) bias test.
} 
$\beta_{0}=0, \beta_{1}=1$, and $\beta_{2}=0 .{ }^{7}$ If the dummy coefficients are non-zero, they contain information that can explain the forecast errors. This indicates that the Fed did not include the information on the state of the economy in the forecasts.

The coefficients of the dummy variables are not significant in any of the current quarter equations (Table 1a), but are significant in all three one-quarter-ahead equations (Table 1b). These results suggest that the Fed does not know what the state of the economy will be in the next quarter. On the other hand, if the Fed did have information on the state of the economy, it was not incorporated into these forecasts because the Wald tests associated with Equation 2 reject the null of informational efficiency.

In the real GDP growth equation for the one-quarter-ahead forecasts (Table 1b), the NBER dummy coefficient is negative, suggesting that the Fed overestimated real GDP growth during recessions. In addition, the constant in that equation is positive and significant, showing that the Fed forecasts underestimated real GDP growth during expansions. In the inflation equation, the ECRI dummy coefficient is positive, indicating that the Fed underestimated inflation when it was increasing (moving from trough to peak in the inflation cycle). Although the constant in that equation is insignificant, it is negative, i.e. the Fed overestimated inflation when it was decreasing. The unemployment equation yields the expected results: the NBER dummy coefficient is positive, because the Fed underestimated unemployment during recessions. These statistical results are in accord with previous findings about systematic errors.

\section{An Asymmetric Loss Function?}

Elliott et al. (2005, 2008) argued that the traditional Mincer-Zarnowitz regression is

\footnotetext{
${ }^{7}$ In applying (2) to the forecasts that have a one-quarter lead, the Newey-West procedure was used to estimate HAC consistent standard errors in (2).
} 
actually a joint test of a symmetric loss function and informational efficiency. The Fed may not have a symmetric loss function, at least with respect to inflation (Capistran, 2008). It is possible that our findings are due to the assumption of a symmetric loss function rather than due to the Fed not incorporating information about the state of the economy into their forecasts.

We explore this possibility using the GMM method and over-identification test described in Elliott et al. (2008) allowing for a general Quad-Quad loss function. The results (Table 2) indicate that for all three variables there is evidence of an asymmetric loss function (except for one-quarter ahead real GDP). An asymmetry parameter of 0.5 suggests symmetric loss; if it is greater than 0.5 then underpredictions are costlier than overpredictions; a value less than 0.5

suggests the reverse. Elliott et al. (2005) showed that the J-test of overidentification is a consistent test of the null hypothesis that the forecasts are efficient. Rejection of the null, as we find in all three cases for the Fed's one quarter ahead forecasts, suggests that the Fed did not know the state of the economy or did not incorporate this information into their forecasts.

\section{An Interpretation}

While the dummy coefficients in the current quarter equations are not significant, they are significant in all of the one-quarter-ahead equations. In order to see how the current quarter forecasts $\left(F_{t, t}\right)$ differ from the one-quarter-ahead forecasts from the previous quarter $\left(F_{t, t-1}\right)$, we examine the revisions in the forecasts. We compare forecasts for the same quarter $(t)$ made at two different times ( $t$ and $t-1)$. The current quarter forecasts are the last ones that were made in each quarter. Consequently, at the end of the quarter there would be virtually complete knowledge about the state of the economy in the previous quarter and considerable information about the current quarter. 
The state of the economy should affect the forecast revision , $F_{t, t}-F_{t, t-1}$, which is then regressed on the state of the economy, $\left(D_{t}\right)$

$$
F_{t, t}-F_{t, t-1}=\delta_{0}+\delta_{1} D_{t}+v_{t}
$$

The coefficients associated with the state of the economy are all significant and have the expected signs (Table 3). ${ }^{8}$ Knowing that the economy was in a recession, the current-quarter GDP forecasts were revised downwards and the unemployment predictions were increased. When inflation was increasing, the forecast for the current quarter was revised upwards. The evidence indicates that when the Fed forecasters had information about the state of the economy, they used the information correctly because these revisions are in the right direction.

\section{Implications and Conclusions}

Based on the forecasts made by the Fed staff, the state of the economy is known by the Fed only in the current quarter and is not incorporated into their one-quarter-ahead forecasts. These results suggest that systematic errors can exist in the forecasts (as found by Joutz and Stekler, 2000), but they may offset each other over the business cycle. Because knowledge about the state of the economy is important for setting monetary policy, the Fed's inability to forecast it one quarter ahead is disconcerting. ${ }^{9}$

\section{References}

Capistran, C, 2008, Bias in Federal Reserve inflation forecasts: Is the Federal Reserve irrational or just cautious? Journal of Monetary Economics, 55, 1415-1427.

Dynan, K. E. and D. W. Elmendorf, 2001, Do Provisional Estimates of Output Miss Economic Turning Points? Federal Reserve Board Finance and Economics Discussion Series No. 2001-52.

\footnotetext{
${ }^{8}$ Similar results were obtained when we converted the forecast revisions into binary variables taking on the value 1 for a positive revision and 0 for a negative revision and using a Probit regression.

${ }^{9}$ Of course, most theoretical models assume that recessions are brought on by some type of unpredictable shock.
} 
Elliott, G., I. Komunjer, and A. Timmermann, 2005, Biases in Macroeconomic Forecasts: Irrationality or Asymmetric Loss? Journal of the European Economic Association, 6(1), 122-157.

Elliott, G., I. Komunjer, and A. Timmermann, 2008, Estimation and Testing of Forecast Rationality under Flexible Loss, Review of Economic Studies, 72, 1107-1125.

Hanson, M. S. and J. Whitehorn, 2006, Reconsidering the Optimality of Federal Reserve Forecasts, Manuscript.

Holden, K. and D.A. Peel, 1990, On testing for unbiasedness and efficiency of forecasts, Manchester School, 48, 120-127.

Joutz, F. and H. Stekler, 2000, An evaluation of the predictions of the Federal Reserve, International Journal of Forecasting, 16, 17-38.

Mincer, J. and V. Zarnowitz, 1969, The Evaluation of Economic Forecasts, in: J. Mincer, ed., Economic Forecasts and Expectations, National Bureau of Economic Research (New York).

Swanson, N. R. and D. van Dijk, 2006, Are Statistical Reporting Agencies Getting It Right? Data Rationality and Business Cycle Asymmetry, Journal of Business \& Economic Statistics, 24(1), 24-42. 
Figure 1.a 1-.d

1a: Real GNP/GDP

Annualized Growth Rate
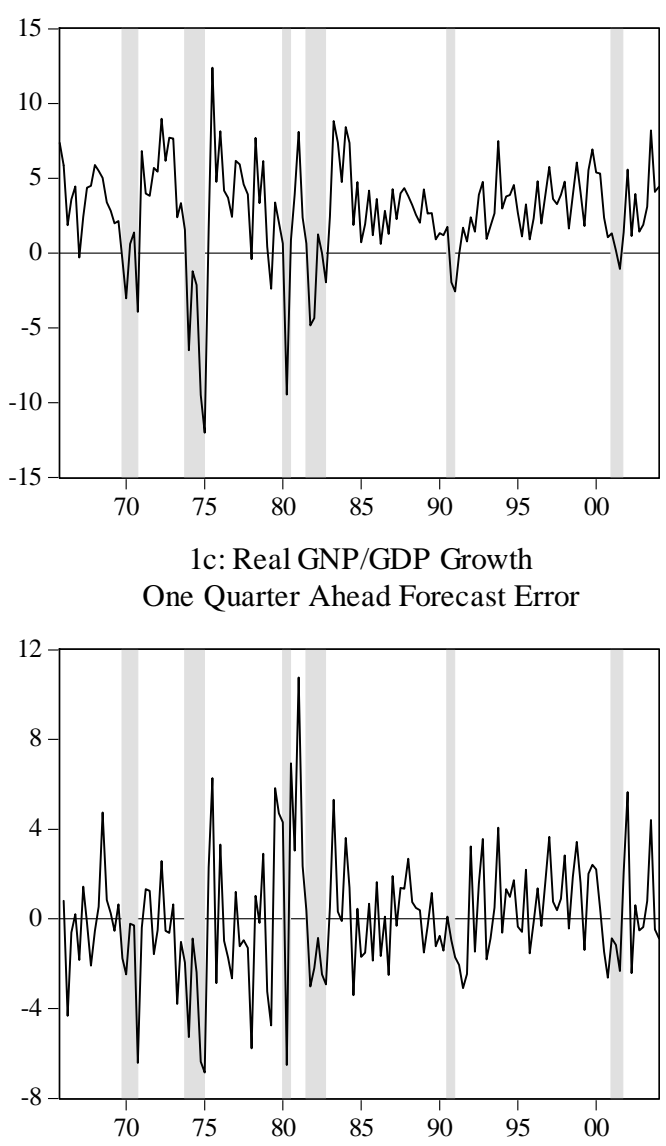

1b: Real GNP/GDP Growth

Current Quarter Forecast Error
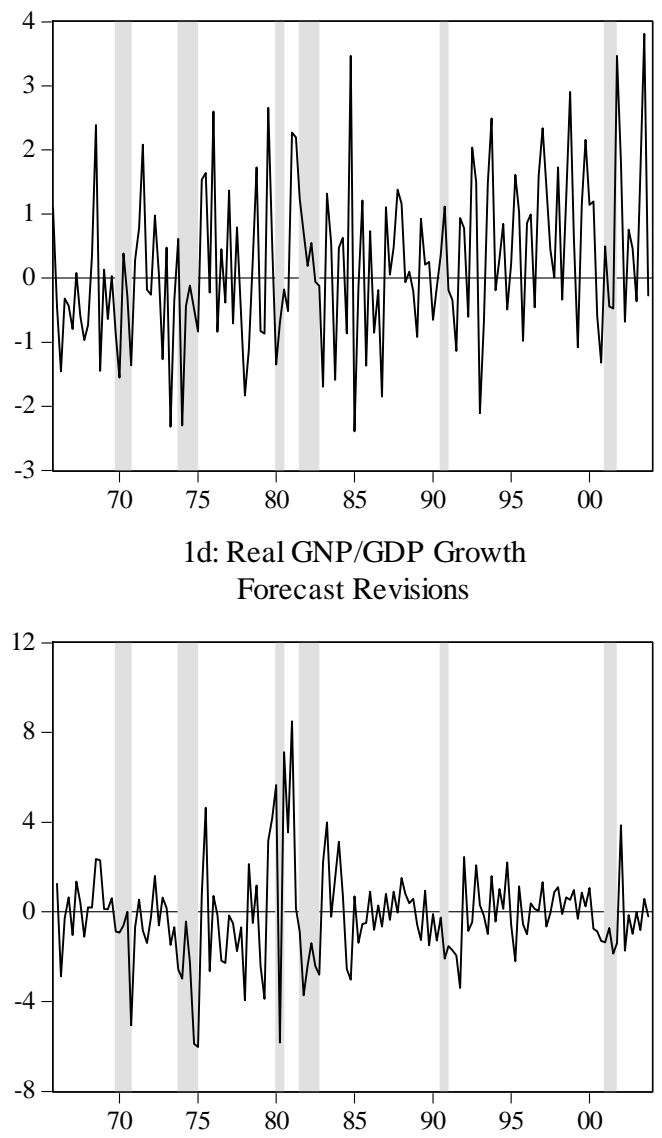
Figure 2.a-2.d

2a: GNP/GDP Deflator

Annualized Inflation Rate

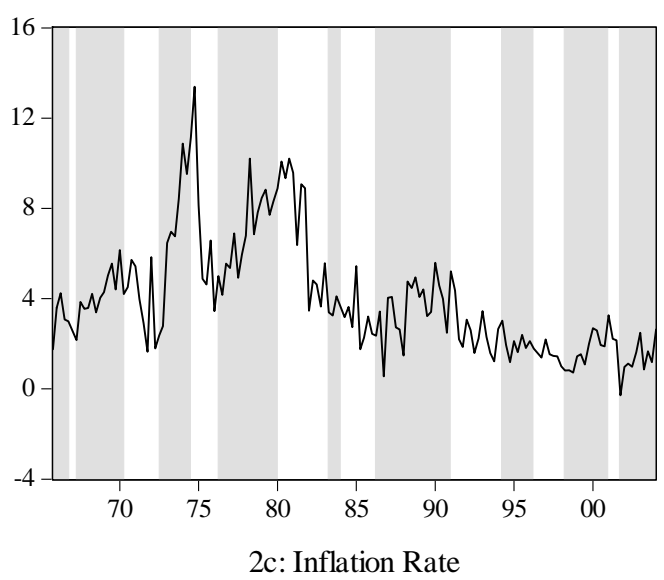

One Quarter Ahead Forecast Error

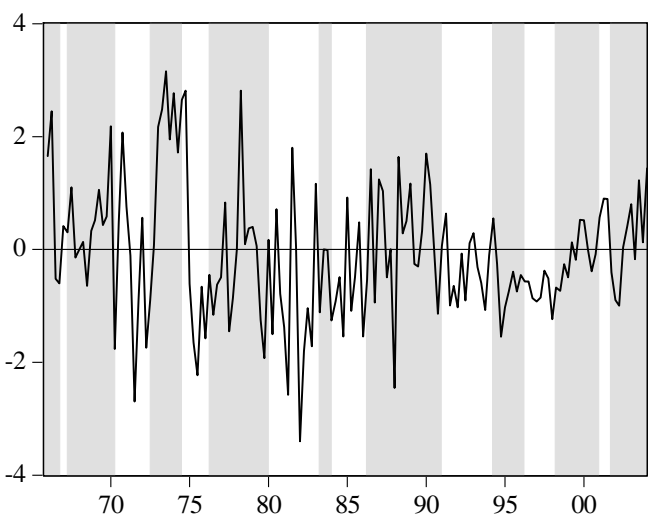

2b: Inflation Rate

Current Quarter Forecast Error
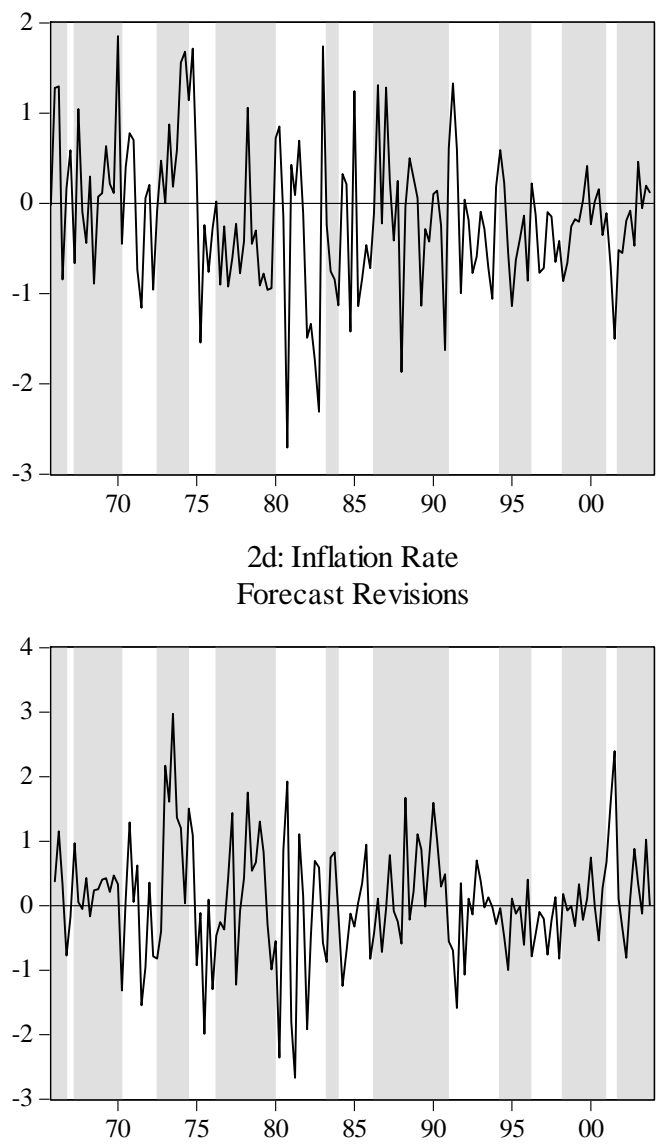
Figure 3.a-3.d

3a: Unemployment Rate
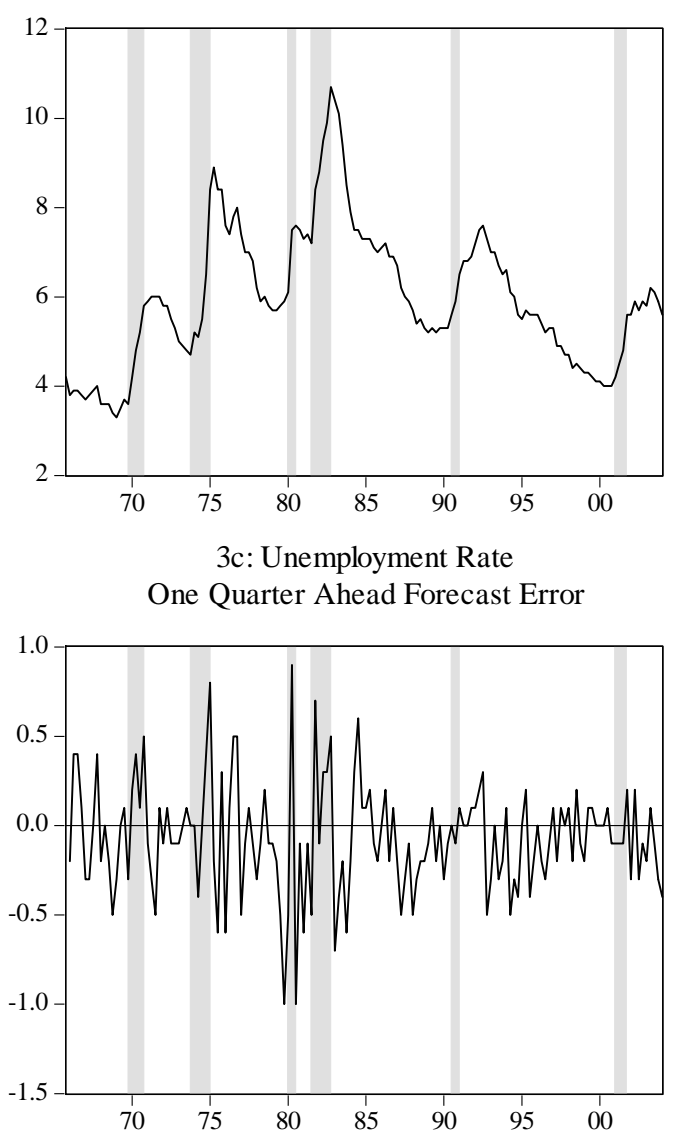

3b: Unemployment Rate

Current Quarter Forecast Error
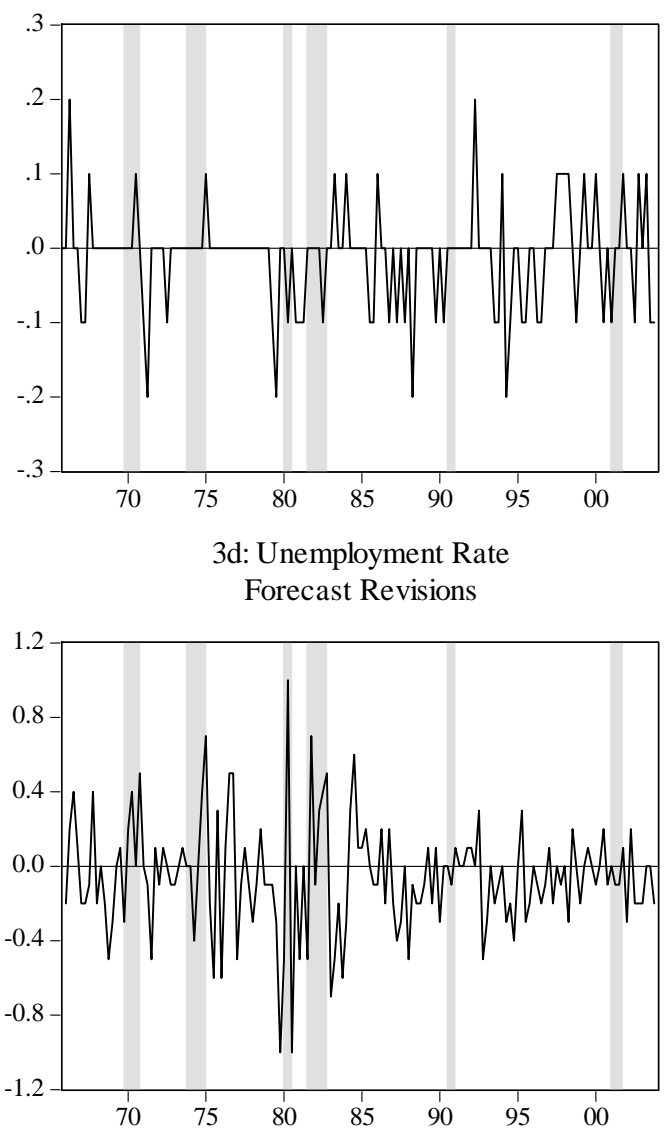
Table 1a: Current Quarter Greenbook Forecasts

Modified Mincer-Zarnowitz Regressions

(Standard Errors in Parentheses)

\begin{tabular}{cccccc}
\hline & Constant & Slope & $\begin{array}{c}\text { NBER } \\
\text { Dummy }\end{array}$ & $\begin{array}{c}\text { Inflation } \\
\text { Dummy }\end{array}$ & $\begin{array}{c}\text { Wald Test } \\
\text { Probability }\end{array}$ \\
\hline RealGrowth & $\begin{array}{c}0.324 * \\
(0.181)\end{array}$ & $\begin{array}{c}0.993^{* * *} \\
(0.042)\end{array}$ & $\begin{array}{c}-0.435 \\
(0.341)\end{array}$ & 0.05 \\
\hline INF & $-0.323^{* *}$ & $\begin{array}{c}1.006 * * * \\
(0.155)\end{array}$ & & 0.218 & 0.03 \\
& $(0.026)$ & & $(0.133)$ & 0.10 \\
\hline UN & 0.002 & $0.997 * * *$ & 0.016 & & \\
& $(0.022)$ & $(0.004)$ & $(0.014)$ & & \\
\hline
\end{tabular}

$*, * *, * * *$ Significant at the $10 \%, 5 \%$, and $1 \%$ level respectively.

Table 1b: One Quarter-Ahead Greenbook Forecasts Modified Mincer-Zarnowitz Regressions

(Newey West Standard Errors in Parentheses)

\begin{tabular}{cccccc}
\hline & Constant & Slope & $\begin{array}{c}\text { NBER } \\
\text { Dummy }\end{array}$ & $\begin{array}{c}\text { Inflation } \\
\text { Dummy }\end{array}$ & $\begin{array}{c}\text { Wald Test } \\
\text { Probability }\end{array}$ \\
\hline RealGrowth & $1.916^{* * *}$ & $0.549^{* * *}$ & $-3.744^{* * *}$ & & $<0.01$ \\
& $(0.585)$ & $(0.160)$ & $(0.578)$ & & $<0.01$ \\
\hline INF & -0.446 & $0.988^{* * *}$ & & $0.665^{* * *}$ & \\
& $(0.301)$ & $(0.065)$ & & $(0.003)$ & $<0.01$ \\
\hline UN & 0.082 & $0.969 * * *$ & $0.194^{* *}$ & & \\
\hline
\end{tabular}

*,**,*** Significant at the $10 \%, 5 \%$, and $1 \%$ level respectively.

\begin{tabular}{ccccc}
\hline \multicolumn{4}{c}{ Table 2: Asymmetric Loss Function } & \\
& $\begin{array}{c}\text { Current } \\
\text { Quarter } \\
\text { Asymmetry } \\
\text { Parameter } \\
\text { (SE) }\end{array}$ & $\begin{array}{c}\text { One Quarter } \\
\text { Ahead } \\
\text { Asymmetry } \\
\text { Parameter } \\
\text { (SE) }\end{array}$ & $\begin{array}{c}\text { Current } \\
\text { Quarter } \\
\text { J-Stat } \\
\text { (P-Value) }\end{array}$ & $\begin{array}{c}\text { One Quarter } \\
\text { Ahead } \\
\text { J-Stat } \\
\text { (P-Value) }\end{array}$ \\
\hline RealGrowth & $0.369 * * *$ & 0.436 & 1.567 & 4.992 \\
& $(0.047)$ & $(0.056)$ & $(0.211)$ & $(0.025)$ \\
\hline INF & $0.651 * * *$ & $0.680 * * *$ & 1.269 & 6.715 \\
& $(0.058)$ & $(0.063)$ & $(0.260)$ & $(0.010)$ \\
\hline UN & $0.648 * *$ & $0.684 * * *$ & 0.631 & 4.213 \\
& $(0.074)$ & 0.049 & $(0.427)$ & 0.040 \\
\hline
\end{tabular}

\footnotetext{
$*, * *, * * *$ Significantly different from 0.5 at the $10 \%, 5 \%$, and $1 \%$ level respectively.
} 
Table 3

Bias Tests for Forecast Revisions

(Standard Errors in Parentheses)

\begin{tabular}{cccc}
\hline & Constant & NBER Dummy & Inflation Dummy \\
\hline RealGrowth & 0.123 & $-1.732^{* * *}$ & \\
& $(0.178)$ & $(0.421)$ & \\
\hline INF & $-0.205^{*}$ & & $0.447^{* * *}$ \\
& $(0.114)$ & & $(0.145)$ \\
\hline UN & $-0.087^{* * *}$ & $0.169 * * *$ & \\
& $(0.026)$ & $(0.061)$ & \\
\hline
\end{tabular}

*, **, *** Significant at the $10 \%, 5 \%$, and $1 \%$ level respectively. 